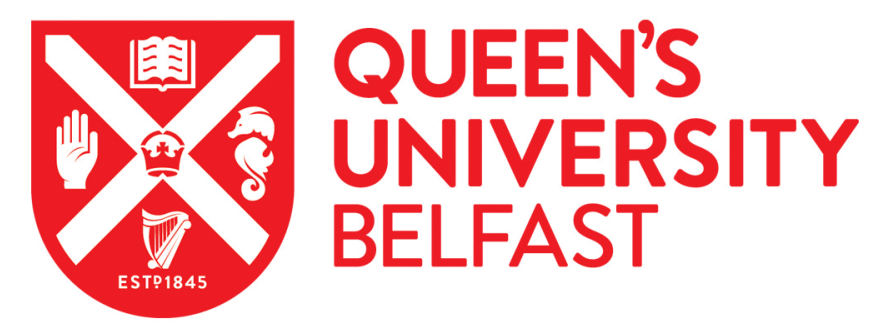

\title{
Advances in Fasciola hepatica research using -omics technologies
}

Cwiklinski, K., \& Dalton, J. (2018). Advances in Fasciola hepatica research using -omics technologies. International Journal for Parasitology. https://doi.org/10.1016/j.ijpara.2017.12.001

\section{Published in:}

International Journal for Parasitology

\section{Document Version:}

Peer reviewed version

Queen's University Belfast - Research Portal:

Link to publication record in Queen's University Belfast Research Portal

\section{Publisher rights}

Copyright 2018 Elsevier.

This manuscript is distributed under a Creative Commons Attribution-NonCommercial-NoDerivs License

(https://creativecommons.org/licenses/by-nc-nd/4.0/), which permits distribution and reproduction for non-commercial purposes, provided the author and source are cited.

\section{General rights}

Copyright for the publications made accessible via the Queen's University Belfast Research Portal is retained by the author(s) and / or other copyright owners and it is a condition of accessing these publications that users recognise and abide by the legal requirements associated with these rights.

Take down policy

The Research Portal is Queen's institutional repository that provides access to Queen's research output. Every effort has been made to ensure that content in the Research Portal does not infringe any person's rights, or applicable UK laws. If you discover content in the Research Portal that you believe breaches copyright or violates any law, please contact openaccess@qub.ac.uk. 


\section{Advances in Fasciola hepatica research using -omics technologies}

2

3

4 Krystyna Cwiklinski ${ }^{1}$ and John P. Dalton ${ }^{1,2}$

5

6

71 - School of Biological Sciences, Medical Biology Centre, Queen's University

8 Belfast, Belfast, Northern Ireland, UK

92 - Institute for Global Food Security (IGFS), Queen's University Belfast, Belfast, 10 Northern Ireland, UK

11

12 Corresponding Author. k.cwiklinski@qub.ac.uk

13

14 Keywords: Fasciola hepatica, helminth, trematode, genome, transcriptome, 15 proteome. 
17 The liver fluke Fasciola hepatica is an economically important pathogen of livestock 18 worldwide, as well as being an important neglected zoonosis. Parasite control is 19 reliant on the use of drugs, particularly triclabendazole (TCBZ), which is effective 20 against multiple parasite stages. However, the spread of parasites resistant to TCBZ 21 has intensified the pursuit for novel control strategies. Emerging -omic technologies 22 are helping advance our understanding of liver fluke biology, specifically the 23 molecules that act at the host-parasite interface and are central to infection, 24 virulence and long-term survival within the definitive host. This review discusses the 25 sequencing technological advances that have facilitated the unbiased analysis of 26 liver fluke biology, resulting in an extensive range of -omics datasets. In addition, we 27 highlight the -omics studies of host responses to $F$. hepatica infection, that, when combined with the parasite datasets, provide the opportunity for integrated analyses of host-parasite interactions. These extensive datasets will form the foundation for future in-depth analysis of $F$. hepatica biology and development and the search for new drug or vaccine interventions.

\section{Introduction}

DNA sequencing technologies have rapidly evolved over the past few decades, stemming from the traditional Sanger methodology used to map the first human genome (Lander et al., 2001; Venter et al., 2001) to the recent highthroughput sequencing technologies such as Roche 454 and Illumina (Reuter et al., 2015) that we use today. More recently, single cell sequencing has emerged, pioneered by Pacific Biosciences and Oxford Nanopore Technologies, through the PacBio and MinION platforms, respectively (Reuter et al., 2015). As the technology for sequencing DNA has progressed, so too have the routine protocols for the extraction of nucleic acids and library preparation (Price et al., 2009); this has allowed sequencing projects to be carried out on even the most challenging species to propagate in the laboratory and those for which it was previously difficult to obtain adequate quantities of nucleic acids. Consequently, the number of sequencing projects undertaken has exploded, including recent ambitious proposals to sequence 10000 vertebrate genomes (Genome 10K project; Koepfli et al., 2015), 5000 
arthropods (i5K project; Poelchau et al., 2015) and all 10500 species of birds (B10K project; Jarvis, 2016), to name but a few.

In the area of parasitology, a similar large-scale collaboration was initiated with the aim of sequencing 50 helminth genomes from human and veterinary parasites of global importance (50 Helminth Genomes Project, 50HGP; http://www.sanger.ac.uk/science/collaboration/50hgp). The advances in sequencing technologies enabled the number of genomes sequenced under this directive to be exceeded. Now in its ninth release, the database housing these genomes, WormBase ParaSite, comprises 134 genomes, representing 114 species (Howe et al., 2017). In addition to acting as a central repository and publically-accessible database for the wider research community, WormBase ParaSite integrates all available genomic and transcriptomic data to provide functional annotation and expression information for each species and thus facilitate comparative genomics analysis.

How we profile the repertoire of transcripts expressed by an organism, at a particular time-point or in response to external cues, has also evolved with advances in sequencing technology. Studies first focused on analysing partial sequences, known as expressed sequence tags (ESTs) derived from libraries of cDNA clones (Parkinson and Blaxter, 2009). In conjunction, serial analysis of gene expression (SAGE) methodology facilitated differential or temporal gene expression studies, as well as the detection and analysis of low abundant transcripts (Sun et al., 2004). However, it was the development of gene expression microarrays that initially instigated high throughput transcriptome analyses that are still used today (Schena et al., 1995; Malone and Oliver, 2011). Since microarrays only detect known gene transcripts immobilised on microchips they are less useful for gene discovery. By contrast, the emergence of RNA sequencing (RNAseq) allowed the analysis of all gene transcripts present within a given sample and now, advanced through the development of next-generation sequencing (NGS) technologies, has largely replaced microarrays for gene transcription analysis.

This emerging array of transcriptome profiling tools has been applied extensively to helminth parasites. Approximately 508,000 ESTs have been generated from Platyhelminth parasites and are housed in the NCBI database 
dbEST (dbEST release 130101; https://www.ncbi.nlm.nih.gov/dbEST/). SAGE methodology has also been employed for the analysis of gene expression across different lifecycle stages (Knox and Skuce, 2005; Williams et al., 2007; Taft et al., 2009). More recently, large scale RNAseq analyses have been completed for a range of Platyhelminth parasites, several of which have been disseminated through the site Helminth.net (Martin et al., 2015). These freely-accessible datasets have complemented ongoing genome projects.

In parallel with techniques to analyse nucleic acids, advances in modern proteomic technologies have allowed the high throughput identification and characterization of complex proteins preparations (Yarmush and Jayaraman, 2002; Brewis and Brennan, 2010). Progress has also been made in developing extraction protocols for soluble and membrane-bound proteins, as well increasing the sensitivity of proteomic technologies, including gel-free protocols that can be carried out on very small amounts of proteins (micrograms) (Scherp et al., 2011; Nature Method of the year 2012. 2013).

By integrating proteomic data with genomic/transcriptomic data functional annotation is more precise and can provide qualitative and quantitative information regarding the expression of genes and their products, as well as data such as the existence of splice variants or the nature of post-translational modifications.

Parasite-host interaction is a complex phenomenon involving molecules produced by both partners. The ability of helminth parasites to invade, migrate and survive within their hosts is expedited by the range of proteins they secrete/excrete. The roles these released proteins play during infection have been investigated in 103 many studies using proteomic tools and have provided a rich source of 104 immunomodulators, diagnostic reagents and vaccine candidates that can be cherry105 picked at will to bring forward into commercialisable biotherapeutics. The available 106 genomic/transcriptomic data, including those present in WormBase ParaSite, 107 complement these proteomic studies, providing publically-available databases that 108 can be used during the identification/annotation process to further our understanding of helminth parasites and their interaction with their hosts.

In this review, we focus on the datasets available for the liver fluke parasite, 111 Fasciola hepatica, and in particular how they are currently analysed and interrogated 
112 to enhance our knowledge of liver fluke biology with a particular emphasis towards

113 elucidating how these parasites invade and survive within their hosts. The lifecycle

114 of this digenean trematode includes a snail intermediate host, within which the 115 parasite undergoes a clonal expansion, and a mammalian definitive host, where the 116 parasite develops into sexually mature adults, releasing 20000-24000 eggs per fluke 117 per day (Boray, 1969). Infection of the mammalian host occurs following the 118 ingestion of the infective encysted stage, the metacercariae. Within the intestine, the 119 parasite excysts, as newly excysted juveniles (NEJ) that migrate across the intestinal 120 wall, across the peritoneal cavity to the liver and bile ducts. F. hepatica is known to 121 infect a broad range of mammalian hosts, including rodents, ruminants, ungulates, 122 kangaroos and primates (Robinson and Dalton, 2009), implying the parasite has 123 evolved a universal process(s) of infection. As a hermaphroditic parasite, $F$. 124 hepatica has the ability to self- and cross-fertilise. In addition, studies have shown 125 that hybridisation with the sister species, Fasciola gigantica can occur, resulting in 126 intermediate or hybrid forms as determined by analysis of mitochondrial genes and 127 intergenic genome sequences (Le et al., 2008; Itagaki et al., 2011; Ichikawa-Seki et 128 al., 2017).

The extensive collection of -omics datasets now available for $F$. hepatica 130 includes the draft genome, stage-specific transcriptomes, and proteomic datasets for 131 the somatic proteome, secretome, extracellular vesicles and glycoproteome of the 132 outer tegumental surface. These datasets can now be used to investigate the 133 complex features of the Fasciola lifecycle, particularly their effects on life history 134 traits that directly impact on gene flow within liver fluke populations, influencing the 135 spread of drug resistance and virulence/pathogenicity traits.

\section{Genomics}

\subsection{The F. hepatica mitochondrial genome}

The characterisation and differentiation of various Fasciola species using 140 morphological features is often unreliable and can only be used for the differentiation 141 of adult parasites found within the bile ducts. Molecular identification based on 142 nuclear ribosomal and mitochondrial genes is a more robust method of species 
143 classification. These molecular tools also provide markers for population genetic 144 studies and epidemiological analysis of Fasciola spp. The complete $F$. hepatica 145 mitochondrial $(\mathrm{mt})$ genome was the first to be sequenced from a trematode species 146 (Le et al., 2001) and has since been used for several population genetics studies of 147 F. hepatica (Walker et al., 2007; Walker et al., 2011; Walker et al., 2012; Bargues et 148 al., 2017). Similarly, the complete $\mathrm{mt}$ genome from $F$. gigantica has been reported 149 (Liu et al., 2014), which now provides species-specific references that can be used in 150 species characterization studies. For example, Liu and colleagues (2014) 151 sequenced the complete $\mathrm{mt}$ genome from an intermediate form of $F$. hepatica and $F$. 152 gigantica found in the Heilongjiang province, China (Peng et al., 2009). Based on 153 intergenic spacer regions (ITS-1 \& ITS-2) this isolate is indeed inferred to be a hybrid 154 between $F$. hepatica and F. gigantica, although comparative analysis between 155 Fasciola spp. mt genomes revealed that the intermediate form was more closely 156 related to $F$. gigantica than to $F$. hepatica. This study shows that hybridisation is not 157 uniform across the genome and that sequence variations at different sites can occur, 158 in this case within the nuclear ribosomal genes and the maternally inherited 159 mitochondrial genes. Thus, the study also highlighted the complexity incurred during 160 hybridization of Fasciola species and challenges that their subsequent 161 characterization presents.

\subsection{Nuclear genome}

To date 33 Platyhelminthes genomes are publically available within 165 WormBase ParaSite, comprising species from the Trematoda, Cestoda, Monogenea 166 and Rhabditophora Classes. Analysis of the genome assembly sizes shows that 167 although individual species vary in respect to their genome size, trends can be observed. In general, the cestode tapeworms have considerably smaller genomes compared the other members of the Phylum Platyhelminthes. The major exception

170 to this statement is Spirometra erinaceieuropaei, which has one of the largest 171 Platyhelminth genomes (1.3 Gb; Bennett et al., 2014). Concerning the Class 172 Trematoda, the blood flukes of the species Schistosoma have smaller genomes 173 compared with other members of the Class. 
Surprisingly, F. hepatica has the largest trematode genome sequenced to date (1.3 Gb; Cwiklinski et al., 2015a). For a parasite such as Fasciola that ensures

176 its own species survival through the daily generation of large numbers of eggs, the 177 evolution of a large genome appears counter-intuitive as it potentially imposes a cost 178 on egg production. The reason for the large genome size has yet to be determined, 179 but our studies indicate that it has not arisen through genome duplication or an 180 increase in the percentage of the genome that is comprised of repeat regions. 181 Although an equivalent number of genes have been identified across the trematode genomes, comparative analysis reveals that increases in genome size are reflective of increases in average exon and intron length, though this alone does not fully explain the increased genome size of the F. hepatica genome. Further analysis of the non-coding regions is required to determine their function and, in particular, their importance in gene regulation (ENCODE Project Consortium 2012).

The recent genome sequencing of $F$. hepatica isolates from the Americas by McNulty and colleagues, confirmed that the large genome size is comparable between fluke isolates (McNulty et al., 2017). Interestingly, the analysis of these American isolates revealed the presence of a Neorickettsia endobacterium within the parasite, which was further demonstrated by immunolocalisation studies that found the bacterium within the eggs, reproductive system and the oral suckers of adult

193 fluke. Consistent with other studies of trematode-Neorickettsia interactions, 194 Neorickettsia could also be detected in the Fasciola eggs by PCR methods. To date 195 no other liver fluke isolates from other geographical locations have reported the 196 presence of any Neorickettsia endobacteria, indicating that the acquisition of this 197 endobacteria may have occurred since the introduction of $F$. hepatica to the 198 Americas. The study by McNulty and colleagues (2017) highlights the potential 199 interaction between Fasciola and endosymbionts/endobacteria and warrants further investigation.

Single nucleotide polymorphism (SNP) analysis of UK F. hepatica isolates, including isolates resistant to the frontline anthelminthic, triclabendazole 203 (Hodgkinson et al., 2013) has revealed high levels of sequence polymorphism in the 204 F. hepatica genome (Cwiklinski et al., 2015a). In particular, a marked overrepresentation of genes with high levels of non-synonymous polymorphism was associated with axonogenesis and chemotaxis, reflecting the changing environments 
the parasite encounters during its migration in the host. This data has recently been complemented by microsatellite analysis that revealed high levels of genetic diversity and gene flow within field isolates in the UK (Beesley et al., 2017). High levels of genetic diversity and gene flow may be important to counter the decline of allele diversity as a result of self-fertilisation (Noel et al., 2017).

The current F. hepatica genome assembly (PRJEB6687; Cwiklinski et al., 213 2015a) is comprised of a large number of scaffolds and contigs $(20,158$ scaffolds 214 and 195,709 contigs, with a scaffold N50 of 204kb), mainly due to the size of the 215 genome and the high percentage of repeat regions, which has hindered the 216 assembly. In the future, utilising sequencing platforms that generate longer reads as 217 well as technologies such as optical mapping should resolve this problem. The 218 sequencing reads can then be mapped to the ten $F$. hepatica chromosomes 219 (Sanderson, 1953), allowing analysis of genome structure and genomic comparison 220 of Platyhelminth genome organisation.

\section{Transcriptomics}

The development of novel control strategies, vaccine and diagnostics aimed 224 at specific $F$. hepatica lifecycle stages, requires an understanding of the genes that 225 are transcribed at each time-point in development as well as their specific 226 transcriptional abundance. Initial studies of gene identification and analysis were 227 based on a limited number of unannotated expressed sequence tags (ESTs; 6819 sequences) generated from adult $F$. hepatica parasites by the Wellcome Trust 229 Sanger Institute (ftp://ftp.sanger.ac.uk/pub/pathogens/Fasciola/hepatica/ESTs/). 230 This EST database was also an essential resource for blasting peptide sequences

231 for F. hepatica proteomic studies (Chemale et al., 2006; Robinson et al., 2009; 232 Chemale et al., 2010; Hacariz et al., 2014; Morphew et al., 2014).

The formative analysis of these EST sequences identified several key 234 molecules of interest for further characterisation, including glutathione transferases 235 (GSTs; Chemale et al., 2006), calcium binding proteins (Banford et al., 2013), mucin236 like proteins (Cancela et al., 2015) and the helminth defence molecule (Robinson et 237 al., 2011; Martinez-Sernandez et al., 2014). Enhancing our understanding of the F. 
238 hepatica lifecycle, Robinson and colleagues (2009) utilised an integrated

239 transcriptomic and proteomic approach based on these adult-specific Fasciola ESTs,

240 to profile the expression of proteins secreted by Fasciola parasites as they migrate

241 through the host. However, this analysis was based on the premise that similarities

242 could be drawn between the proteins expressed by the adult parasites residing in the

243 bile ducts and those expressed by the migrating NEJ parasites. Utilising an adult-

244 specific database, especially one with a limited number of sequences, likely resulted

245 in NEJ-specific proteins being overlooked.

246 In 2010, Cancela and colleagues (2010) reported the generation of 1684

247 ESTs from the excysted NEJ. The limited number of ESTs is reflective of the

248 amount of total RNA that could be extracted from 1200 NEJ and subsequently used

249 for cDNA synthesis (200ng). Nevertheless, analysis of these sequences identified

250 several sequences that had not been previously reported within the adult ESTs,

251 implying that they were NEJ-specific. Specifically, several cathepsin cysteine

252 proteases and antioxidant enzymes were characterised and showed that $F$. hepatica

253 has adapted stage-specific proteases and enzymes to utilise throughout its lifecycle.

254 The identification of novel stage-specific genes within this study highlighted the need

255 for more extensive lifecycle stage-specific transcriptomes to further Fasciola 256 research.

257 Led by the developments in sequencing technologies, Young and colleagues 258 (2010) reported the first extensive adult $F$. hepatica transcriptome sequenced using 259454 sequencing technology. In comparison to the 6819-unannotated adult-specific 260 EST sequences available, this study generated a total of 590, 927 high quality reads 261 that were clustered into approximately 48,000 sequences, of which 15,423 262 supercontigs of $745 \mathrm{bp}( \pm 517 \mathrm{bp})$ were enriched for open reading frames (ORF). 263 These sequences were subjected to extensive homology searches and protein 264 prediction, using tools such as InterProScan, gene ontology (GO) and KOBAS 265 (KEGG Orthology-Based Annotation System) to annotate the predicted proteins. 266 Based on the publically available datasets at the time, approximately $44 \%$ of the 267 sequences were classified, identifying proteins representative of the adult stage 268 parasite. In keeping with the fact that $F$. hepatica expresses a range of cathepsin 269 cysteine proteases, several cysteine peptidase family members were identified within 270 the adult transcriptome. The predicted protein sequences were also screened for 
271 signal peptide and transmembrane domains to profile those proteins secreted by 272 classical pathways within the ES proteins by the adult parasites; this analysis 273 identified all the 160 ES proteins reported by Robinson et al. (2009). Importantly, 274 comparing the Robinson et al. (2009) proteomic dataset with this more extensive 275 adult $F$. hepatica database resulted in the annotation of previously unclassified 276 proteins, including a group of fatty acid binding proteins and redox antioxidant 277 enzymes. A further 18,347 contigs have been generated using 454 sequencing of 278 adult fluke cDNA by Wilson et al. (2011) during their interrogation of the adult 279 tegument. This more extensive dataset for adult $F$. hepatica has been interrogated 280 by various research groups and has led to the identification of a range of proteins 281 including, SCP/TAPS proteins (Cantacessi et al., 2012), glutathione transferases 282 (Morphew et al., 2012) and cathepsin cysteine proteases (Morphew et al., 2011).

The available transcriptome data and subsequent analysis for Fasciola spp. has since been further improved with the development of short read Illumina sequencing that has increased sequence depth and coverage (Reuter et al., 2015). Investigation of the similarities between $F$. hepatica and F. gigantica, particularly those molecules important at the host-parasite interface, has been carried out following the first characterisation of the F. gigantica adult transcriptome (Young et al., 2011). Similarly, in depth Illumina sequencing has been applied to the study of virulence and immunomodulation-related genes of adult $F$. hepatica, identifying 62 previously uncharacterised virulence-related genes. In silico characterisation, 292 subsequently implied that these genes have immunomodulatory properties since 293 they were comparable to various immune related molecules, including cytokines and 294 immune receptors (Hacariz et al., 2015).

In particular, the development of Illumina sequencing technology has advanced our knowledge of other $F$. hepatica lifecycle stages that have been previously difficult to analyse. We have reported the sequencing of several early 298 lifecycle stages, namely the infective metacercariae stage, the NEJ parasites $1 \mathrm{hr}$, $2993 \mathrm{hr}$ and $24 \mathrm{hr}$ post-excystment, as well as juvenile parasites at 21-day post infection 300 and adult parasites which has provided a transcriptional profile of $F$. hepatica during infection (Cwiklinski et al., 2015a). Differential gene transcription analysis showed that the parasite regulates the transcription of many of its genes with progressively 
more genes being highly transcribed as the parasite rapidly grows and develops in preparation for migration through the host liver (>8000; Cwiklinski et al., 2015a).

The integration of transcriptome data with the $F$. hepatica genome has also revealed that gene family expansion is a key feature of $F$. hepatica adaptation and survival; we have shown that $F$. hepatica transcribes different members of these gene families during different stages of the lifecycle (Cwiklinski et al., 2015a). Key examples of such expanded gene families are the cathepsin cysteine proteases and the microtubule-related alpha and beta tubulins genes. Biochemical analysis of the family of cathepsin proteases has shown that the different clades have evolved distinctive peptidolytic activity specific to the requirements of different lifecycle stages (Robinson et al., 2008). Similarly, the transcription of the diverse range of beta tubulin isotypes that are temporally regulated could explain the stage-specific efficacy of benzimidazole anthelminthics (Sanabria et al., 2013).

Coupled with comprehensive proteomic analyses, a current focus of our work is to investigate the infective and invasive lifecycle stages, namely the metacercariae and NEJ to elucidate how the parasite prepares for infection and undergoes alterations to ensure its own survival (Cwiklinski and Dalton, unpublished). In depth interrogation of the transcriptome data available for these lifecycle stages has shown that the infective stage, metacercariae, is metabolically active and that early juvenile stages regulate the transcription of metabolic pathways, particularly those related to aerobic energy metabolism (Cwiklinski and Dalton, unpublished).

McNulty et al. (2017) reported a transcriptome analysis of $F$. hepatica eggs, metacercariae and adult stages, as part of their genome characterisation of American F. hepatica isolates, and identified several gene sets that were overexpressed by specific lifecycle stages. In particular, consistent with our analysis (Cwiklinski et al., 2015a), the cathepsin proteases were found to be highly regulated; different clade isotypes were over-expressed by the metacercariae compared with the adult parasite. The most significantly over-expressed gene in eggs was found to be the rate-limiting enzyme of the pentose phosphate pathway, glucose-6-phosphate dehydrogenase.

Recently, there has been an interest in extracellular vesicles within parasite secretomes and the role they play at the host-parasite interface (Marcilla et al., 2014; 
335 Coakley et al., 2015). Extracellular vesicles (EVs) enable cell-to-cell communication 336 by transferring proteins, lipids and microRNA (El Andaloussi et al., 2013; Record et 337 al., 2014; Huang-Doran et al., 2017). At least two sub-populations of EVs with 338 different protein content have been shown by centrifugation methods to be secreted 339 by $F$. hepatica, including large EVs released from the parasite gut (15K EVs) and 340 smaller exosome-like vesicle released from the tegumental surface (120K EVs) 341 (Marcilla et al., 2012; Cwiklinski et al., 2015b). Transcriptomic analysis of the genes 342 involved in the EV biogenesis pathway suggests that the synthesis of these two sub343 populations of EVs occur via separate pathways, namely ESCRT and lipid344 related/ESCRT-independent pathways, respectively (Cwiklinski et al., 2015b; de la 345 Torre-Escudero et al., 2016).

Further analyses of Fasciola microRNAs (miRNAs) has been carried following 347 the generation of three small RNAseq libraries from adult parasites (Xu et al., 2012; 348 Fromm et al., 2015), the NEJ (Fontenla et al., 2015) and extracellular vesicles 349 isolated from adult parasite secretion (Fromm et al., 2015). These studies have 350 identified 52 non-coding microRNAs (miRNAs) corresponding to 32 metazoanconserved miRNA families (Fromm et al., 2017). In addition, five $F$. hepatica-specific sequences were identified. Comparative analysis with $F$. gigantica indicates that these five sequences are specific to $F$. hepatica and are not shared across the 354 Fasciola genus. Correspondingly, eight miRNAs have been identified as $F$. gigantica-specific (Xu et al., 2012). Whether or not these Fasciola-specific miRNAs are important for infection of the mammalian host has yet to be determined. Throughout the lifecycle the abundance of the miRNAs expressed by $F$. hepatica varies, indicating stage-specific roles (Fromm et al., 2017), with those miRNAs present within the extracellular vesicles most likely important for host-parasite interactions. In particular, the predicted targets of five immuno-regulatory miRNAs found to be enriched within the EV warrant further investigation (Fromm et al., 2015; Fromm et al., 2017).

\section{Proteomics}


and evasion from immune responses. While the early migrating stages of $F$. hepatica are mainly tissue feeders, adult parasites residing in the bile ducts are obligate blood feeders. The adult flukes are readily recovered from the bile ducts of infected livestock and ES proteins are released in abundance when the adult parasites are maintained in culture medium (even microgram quantities can obtained

372 from 10 adult parasites in vitro). Thus, the ES proteins of adult parasites have been 373 extensively studied using proteomic tools. Early studies of $F$. hepatica proteins used radio-metabolic labelling to differentiate between the proteins of the various lifecycle stages (Irving and Howell, 1982; Dalton et al., 1985). Isoelectric focusing and densitometry were also carried out to characterise the ES proteins secreted by flukes maintained in different mammalian systems, namely llamas, rats, mice and cattle, which showed a different banding pattern (Lee et al., 1992a; Lee et al., 1992b). Jefferies and colleagues $(2000 ; 2001)$ improved this analysis using two-dimensional gel electrophoresis and subsequent characterisation and annotation of protein spots to identify a range of cathepsin $L$ proteases, superoxide dismutase, peroxiredoxin, glutathione S-transferases and fatty acid binding proteins. This study formed the basis for further in-depth analyses of these protein families using modern proteomic techniques and phylogenetic tools to elucidate how these protein families have diverged and adapted (Chemale et al., 2006; Robinson et al., 2008; Marcilla et al., 2008; Morphew et al., 2011; Morphew et al., 2012; Morphew et al., 2013; Cwiklinski et al., 2015b; Morphew et al., 2016; Di Maggio et al., 2016). Furthermore, proteomic analysis of the proteins within the extracellular vesicles released within the secreted/excreted proteins has revealed that the $15 \mathrm{~K}$ and $120 \mathrm{~K}$ sub-populations of EVs released by $F$. hepatica vary in their protein cargo composition (Cwiklinski et al., 2015b).

Analysis of the adult liver fluke secretome has been used to assess the mode 393 of action of the anthelminthic drug triclabendazole (TCBZ), and suggest that TCBZ 394 broadly effects liver fluke metabolism (Chemale et al., 2010). In particular, protein 395 signatures of liver fluke parasites susceptible and putatively-resistant to TCBZ can 396 be discerned based on the parasite's response to the TCBZ metabolite 397 triclabendazole sulphoxide (TCBZ-SO) (Morphew et al., 2014). Parasite susceptibility to TCBZ characterised by lethal activity was indicated by the presence of actin, gelsolin, DJ-1 and triose phosphate isomerise, whereas putative resistance 
400 characterised by sub-lethal activity was indicated by the presence of calreticulin, 401 cathepsin $L$ proteases and enolase. These highly-specific protein profiles provide 402 potential markers that can be used for future TCBZ efficacy studies.

403 In contrast to the large amount of protein secreted by the adult parasites, 404 analysis of the early developmental and migratory stages of $F$. hepatica is more 405 challenging given their small size and difficulty in locating them in hosts tissues. 406 Accordingly, fewer proteomic studies have been reported for these stages. The 407 molecular investigation of egg embryonation, however, characterised 28 proteins 408 within the somatic proteome from 200,000 eggs (Moxon et al., 2010), and revealed 409 that protein complexity increases as eggs mature, consistent with the development 410 of the miracidia stage. This study also demonstrated that eggs have a substantially 411 different protein profile to the other developmental stages of $F$. hepatica (Moxon et 412 al., 2010). Similarly, a study of the secretome of an intra-molluscan stage, in vitro 413 transformed mother sporocysts, required 388,000 parasites to generate sufficient 414 protein for analysis (Gourbal et al., 2008). Seventeen of the most abundant proteins 415 were analysed, in particular two antioxidant enzymes, Cu/Zn superoxide dismutase 416 and thioredoxin (Gourbal et al., 2008). These enzymes were previously reported 417 within the adult secretome (Jefferies et al., 2001; Robinson et al., 2009), suggesting 418 a uniform process of detoxification of reactive oxygen species.

The development of proteomic tools and the accessibility of $F$. hepatica 420 parasites have facilitated the expansion of the available proteome datasets for the 421 NEJ migratory stages. Profiling the proteins secreted by the early infective stages, 422 namely the NEJ 24hr post-excystment and juvenile fluke 21 days post-infection with 423 those of adult parasites has allowed stage-specific proteins to be determined 424 (Robinson et al., 2009). A greater level of protein complexity was observed within 425 the juvenile secretome (45 proteins), compared with the NEJ $24 \mathrm{hr}$ (29 proteins) and 426 adult secretome (22 proteins), with a wider range of cathepsin isotypes and 427 antioxidant enzymes being secreted. This is consistent with the migratory and 428 feeding traits of this stage, and the upregulation of gene transcription observed 429 during this stage (Andrews, 1999; Cwiklinski et al., 2015a). The NEJ 24hr 430 secretome profile also confirmed the initial characterisation by $\mathrm{N}$-terminal 431 sequencing of the NEJ secreted proteins carried out in the Meeusen laboratory 
432 (Tkalcevic et al., 1995), which described an abundance of cathepsin $\mathrm{L}$ and 433 asparaginyl endopeptidase cysteine proteases.

434 Facilitated by the sequencing of the F. hepatica genome, Di Maggio and 435 colleagues (2016) recently reported a comprehensive analysis of the secreted 436 proteins of adult liver fluke and NEJ 48hr post-excystment and compared these with 437 the somatic proteome of the NEJ 48hr. Using gel free proteomic techniques, this 438 study identified 202 proteins within the adult secretome, 90 proteins within the NEJ $43948 \mathrm{hr}$ secretome and 575 proteins in the somatic proteome of the NEJ 48hr. 440 Consistent with other secretome analyses, a range of proteases and protease 441 inhibitors were detected by both developmental stages, representing $>70 \%$ and $442<10 \%$ of the total protein secreted, respectively. Furthermore, previously unreported 443 proteins were identified within the NEJ somatic proteome, including structural 444 proteins and proteins related to metabolism, expanding our knowledge of this 445 lifecycle stage.

Untangling the complexities of host-parasite interactions is key to furthering our understanding of how this helminth evades the host immune system. The adult 448 liver fluke parasites reside within the bile ducts immersed in bile composed of bile 449 acids, phospholipids, cholesterol, bilirubin and inorganic salts (Farina et al., 2009). 450 Safe from the host's immune response (Andrews, 1999; Correia et al., 2001), 451 proteomic analysis has shown that the adult secretome in the bile of sheep infected 452 with F. hepatica is dominated by cathepsin L proteases (Morphew et al., 2007) 453 similar to that shown in vitro (Robinson et al., 2009; Morphew et al., 2011).

Key to the survival within the mammalian host is the parasite tegument that 455 can be rapidly turned over to prevent attachment of immune effector cells. 456 Proteomic characterisation of the adult tegument was found to be enriched in 457 structural proteins, transporters, proteins involved in secretory pathways and 458 antioxidant enzymes (Wilson et al., 2011; Hacariz et al., 2012). A similar range of 459 proteins were also identified within the somatic proteome of the outer tegumental 460 surface of NEJ (Hernandez-Gonzalez et al., 2010). Furthermore, recent analysis 461 has been carried out on the tegumental immunoprecipitate formed following the 462 incubation of live adult $F$. hepatica flukes in purified IgG from $F$. gigantica-infected 463 Thin Tailed sheep (Cameron et al., 2017). This study identified several molecules 
464 consistent with previous analyses of the tegument (Wilson et al., 2011; Hacariz et al., 465 2012), as well as a range of proteins associated with $F$. hepatica exosomes (15K 466 EVs; Cwiklinski et al., 2015b). In addition, it highlighted the cross-reactivity between 467 antibodies elicited against $F$. gigantica during infection of Thin Tailed sheep and $F$. 468 hepatica tegumental proteins, and raised the interesting question of whether different 469 proteins and EV components are secreted/released under different 'environmental' 470 situations.

\section{Glycomics}

To date F. hepatica glycomic analyses have focussed on the outer surface of the parasite, the glycocalyx, that is rich in glycoproteins and glycolipids (Threadgold, 1976). Analysis has shown that the tegumental surface is highly glycosylated, with an abundance of mannose-rich $\mathrm{N}$-linked glycoproteins present on the surface, spines and suckers (Garcia-Campos et al., 2016; Ravida et al., 2016a; Ravida et al., 2016b). The exact role these $\mathrm{N}$-glycoproteins play at the host-parasite interface is currently unknown, though parasite glyco-conjugates that been implicated in evading the host immune response (van Die and Cummings, 2010). Moreover, blocking of the N-glycans on the surface on the NEJ using lectins has been shown to inhibit their migration across the intestinal wall (Garcia-Campos et al., 2017). Studies of the $F$. hepatica glycans have shown that they have immune modulatory properties modulating toll-like receptor-induced maturation of dendritic cells through carbohydrate specific receptors (CLR) (Rodriguez et al., 2015; Ravida et al., 2016a; Rodriguez et al., 2017). In contrast to the analysis of the F. hepatica N-glycans, the composition of the O-glycans has yet to be determined, though potential sites have been identified within the glycoproteins of the tegument (Ravida et al., 2016b).

The glycocalyx is also rich in glycolipids that are highly antigenic (Wuhrer et al., 2003) and share terminal Gala1-4Gal and Galß1-6Gal motifs with cestodes that result in serological cross-reactivity (Wuhrer et al., 2004). As well as being crossreactive with other members of the Phylum Platyhelminthes, these glycolipids also

493 mimic mammalian-type glycolipids (Wuhrer et al., 2001; Wuhrer et al., 2004), 494 facilitating parasite survival. 


\section{Proteomic and transcriptomic analysis of host responses to F. hepatica}

Several recent studies have utilised -omics approaches to investigate the responses of the host during infection with $F$. hepatica with the aim to elucidate host responses that mirror the stage of infection and the developmental changes that occur within the advancing parasite. These large-scale investigations of the host responses give an unbiased global view of the effects of fasciolosis on host immune tissues, and have revealed novel aspects of pathogenesis associated with infection. In addition, these approaches are being used to evaluate potential vaccine candidates, identifying the genes involved in conferring protection (Wesołowska et al., 2013; Rojas-Caraballo et al., 2017).

Transcriptomic responses within macroscopic lesions of $F$. hepatica-infected liver at 8 weeks post infection (wpi) in sheep revealed that gene expression is highly regulated (Alvarez Rojas et al., 2015), consistent with comparable microarray studies of mice (Rojas-Caraballo et al., 2015). Several processes characteristic of acute fasciolosis and upregulated in response to the damage caused by the parasite were identified. Genes corresponding to fibrosis and tissue repair were found to be upregulated, consistent with the subsequent tissue regeneration required following

513 the invasive migration of the parasite. In keeping with observations that helminth 514 infections typically skew host immune responses towards a Th2 type, genes associated with Th2 differentiation and B cell activation were found to be

516 upregulated, while Th1 type responses were down-regulated. Interestingly, this 517 study also reported that an increased abundance of circulating reticulocytes is 518 associated with the blood feeding activity of $F$. hepatica, which can cause anaemia. 519 Increased transcription of haemoglobin-related genes and four genes putatively associated with Fanconi anaemia were also observed.

In other investigations of the host responses to fasciolosis, two recent studies 522 analysed the transcriptomic responses of ovine peripheral blood mononuclear cells 523 (PBMC) at stages throughout infection (Alvarez Rojas et al., 2016; Fu et al., 2016).

524 Despite different protocols being used for sample preparation, RNA extraction and 525 subsequent analysis of the RNAseq data, both studies reveal that gene transcription 526 is highly regulated during $F$. hepatica infection of sheep, particularly during acute 
527 infection (1-2 wpi). Both studies also observed the upregulation of genes associated

528 with TGF beta signalling, including the genes TGF beta, collagen type 1 and the 529 downstream SMAD signalling genes. These genes play a major role in fibrosis, 530 which were also observed in the transcriptome analysis of infected liver described 531 above (Alvarez Rojas et al., 2015). Upregulation of genes associated with the 532 complement and coagulation cascades, chemokine signalling pathway and cytokine533 cytokine receptor interaction pathway were also reported by Alvarez Rojas et al. 534 (2016).

535 Consistent with the polarization of immune responses towards a Th2 type, the 536 gene encoding inducible nitric oxide synthase (iNOS) was shown to be down537 regulated in response to infection with $F$. hepatica at both acute and chronic stages 538 in the study by $\mathrm{Fu}$ et al. (2016). Transcription of Th17 related genes were also 539 down-regulated, suggesting that $F$. hepatica is able to inhibit the differentiation and 540 stability of Th17 cells. In contrast with the study by Fu and colleagues (2016), 541 however, genes encoding interleukins, particularly those related to Th2 type 542 responses, such as IL-4, were not reported by Alvarez Rojas et al. (2016) to be 543 differentially expressed at statistical levels. This difference may reflect the different 544 protocols used to process the PBMCs for RNA extraction, namely processing fresh 545 cells versus storage in RNAlater, which may have had an effect on the stability of 546 gene expression profiles (Debey-Pascher et al., 2011; Eikmans et al., 2013). 547 Equally, the type of strategy used for sequence analysis may contribute to the 548 differences observed.

549 As infection by $F$. hepatica progresses, the amount and composition of 550 immune cells present both within the peritoneal cavity and circulating in the 551 peripheral blood shifts to an abundance of eosinophils, which is associated with a 552 polarisation to Th2 type immune responses. Differential eosinophil cell counts were 553 only reported in the Alvarez-Rojas et al. study (2016), and showed the infected 554 animals had substantially more eosinophils than the control non-infected animals. At $5554 \mathrm{wpi}$, the eosinophil count in the infected group ranged from 12-39\% compared with 556 the control group counts of $1-5 \%$. Therefore, the changes of transcriptomic 557 response are reflective of both a change in transcription during infection as well as a 558 change in the number and type of cells within the PBMC fraction and must be 559 interpreted accordingly. 
561 helminth parasites, in particular sheep and cattle are genetically more variable, at 562 both individual animal level and between breeds. This can have a significant effect 563 on how an animal or animal breed responds to infection with $F$. hepatica (Ardia et al., 564 2011). In the case of the two studies analysing transcriptomic responses in PBMC, 565 each used different sheep breeds sorted into groups of four animals. To address the 566 possible between-animal variation Alvarez Rojas et al. (2016) employed two 567 strategies to analyse their data; (1) assessment of each animal as an independent 568 experiment and (2) treating each group (control non-infected and infected) as 569 biological replicates. Differentially expressed genes identified by both strategies 570 were then used for further analysis, resulting in the identification of 183 and 76 571 genes differentially expressed at 2 wpi and 8 wpi, respectively. In comparison, the 572 study by Fu et al. (2016), which compared animals as biological replicates, identified 5736490 differentially expressed genes at $1 \mathrm{wpi}$, indicating that many genes of interest 574 were overlooked by the stringent process employed by Alvarez-Rojas et al. (2016). 575 However, the sheep breed-specific responses may also be a factor in the differences 576 observed between these trials. Therefore, it is important for studies of host-parasite 577 interactions in ruminants that sufficient numbers of animals are used and that the 578 type of analysis utilised is appropriately considered and validated.

The host responses to the migrating parasites within the peritoneal 580 compartment during early infection and in the bile ducts consistent with chronic 581 infection have also been investigated using proteomic tools. Early fasciolosis is 582 characterised by the migration of $F$. hepatica through the intestinal wall to the liver 583 via the peritoneal cavity. Proteomic analysis of the peritoneal fluid from sheep 584 infected by $F$. hepatica at 18 days post infection (dpi) identified an abundance of 585 proteins associated with the complement system and proteins associated with the 586 liver extracellular matrix (ECM) (Ruiz-Campillo et al., 2017). The presence of 587 proteins associated with the liver ECM, including collagen VI, fibronectin and 588 fibrocystin, is likely the result of the damage caused by the parasite as it invades and 589 migrates through the liver. Intriguingly, this study also detected two ECM-related 590 molecules, periostin and vascular cell adhesion protein 1 (VCAM-1), that mediate 591 leukocyte infiltration and are associated with marked eosinophilia, which warrant 592 further investigation as biomarkers of infection. 
Systemic responses have been analysed using proteomic tools to identify

594 biomarkers of infection within the serum. Rioux et al. (2008) showed that there were 595 significant changes within the sera beginning within 3 weeks of infection, consistent 596 with the transcriptomic analysis of PBMCs that highlighted a greater level of 597 differential gene expression during acute infection (Fu et al., 2016; Alvarez Rojas et 598 al., 2016). These striking changes also coincide with marked expression of $>8000$ 599 genes that accompany the rapid growth and development of $F$. hepatica in the first 600 three weeks of infection (Cwiklinski et al., 2015a). Two markers of particular interest, 601 namely transferrin and apolipoprotein A-IV (Apo A-IV), were upregulated during this 602 early period (Rioux et al., 2008). Transferrin is associated with the anaemia caused 603 by the blood feeding parasites, whereas Apo A-IV is associated with regulation of 604 appetite within the intestine of mammals (although studies in rats and mice insinuate 605 a possible role within the liver; VerHague et al., 2013). In comparison, levels of 606 transferrin detected within the bile by Morphew et al. (2007) were reduced compared 607 with levels in the serum, further highlighting that the data can vary significantly 608 depending of the sample type (serum, bile, peritoneal fluid etc) and time of infection.

\section{Concluding remarks}

Over the last few decades major advances that have been made through -

612 omics technologies have provided the liver fluke community with an extensive array 613 of datasets that can be interrogated to further our understanding of liver fluke biology 614 (Fig. 1). The number of genes encoded within the $F$. hepatica genome has been 615 clarified. In particular, this information has been crucial in elucidating gene family 616 organisations, which in the past have been complicated by the large number of gene 617 sequences of similar classification present within the NCBI database. In addition, 618 the genes transcribed by $F$. hepatica have been found to be highly regulated 619 throughout the lifecycle within the mammalian host. This knowledge is vital for our 620 continuing efforts to develop control strategies that, in particular, target the early 621 stage parasites. Proteomic analysis of the secreted/excreted proteins has 622 highlighted key molecules that play an important role at the host-parasite interface. 623 Biochemical characterization of these key molecules has also revealed stage624 specific adaptations, including the activity of cathepsin $L$ proteases that includes 
625 collagenolytic activity specific to the juvenile parasites and haemolytic activity 626 restricted to the adult parasites (Robinson et al., 2008). It has also revealed some 627 unexpected adaptations such as the kunitz-type serpin inhibitors that have inhibitory 628 activity against cathepsin L cysteine proteases and not serine proteases (Smith et 629 al., 2016).

However, the function of a large proportion of $F$. hepatica genes and the 631 proteins they encode still remain unknown. In general, these genes only share 632 homology with uncharacterised genes from other Platyhelminthes, indicating that 633 they are Phylum-specific. Further investigation is therefore required to decipher the 634 function these genes play and specifically their importance for host-parasite 635 interactions. This can be achieved utilising post-genomic tools such as RNA 636 interference (RNAi) and CRISPR, as well as protein structural analysis to increase 637 our knowledge of these uncharacterised genes, facilitating the annotation of 638 Platyhelminthes datasets. Furthermore, the addition of this information into the 639 various software packages available for omics analyses, such as STRING 640 (Szklarczyk et al., 2015) and PANTHER (Mi et al., 2017) where there is a current 641 lack of data relating to the Phylum Platyhelminthes, is essential to expand our 642 knowledge of parasite protein-protein interaction networks.

How parasites regulate their genes, specifically in response to their 644 environment, particularly the host immune response, is becoming an area of intense 645 interest. In particular, this analysis has encompassed understanding the epigenetic 646 process of gene regulation, through DNA methylation, histone modification and non647 coding RNA associated with gene silencing (Egger et al., 2004). The role these 648 epigenetic processes play to facilitate Fasciola invasion and survival has yet to be 649 investigated. However, studies of closely related Platyhelminthes have indicated 650 that it warrants further investigation. In particular, the study of DNA methylation 651 across the Phylum Platyhelminthes has shown that cytosine methylation is a 652 functionally conserved epigenetic feature (Geyer et al., 2013). Furthermore, recent 653 analysis of the epigenome of Schistosoma mansoni cercariae has revealed that 654 histone modifications play an important role in regulating the transcription of genes, 655 with the cercariae being transcriptional inactive (Roquis et al., 2015). In-depth of 656 analysis of the Fasciola genome has already revealed an array of non-coding small 657 RNAs that may play a part in the post-transcriptional regulation of Fasciola genes 
658 and/or be important for the regulation and manipulation of the mammalian host. 659 Similar analysis of the epigenome of the different lifecycle stages will show if there 660 are any lifecycle stage-regulatory factors associated with liver fluke gene regulation.

661 For the future development of control strategies, a greater understanding of 662 host helminth interactions is paramount. This review has discussed the large-scale 663 datasets available for the study of liver fluke infection, from both the parasite and the 664 mammalian host. Going forward the analyses of these data should be integrated to 665 elucidate the delicate interplay that occurs during infection and to determine if the 666 pathogenicity/virulence of liver fluke isolates within field populations plays a role in 667 this interaction.

668 


\section{$670 \quad$ Figure Legend}

671 Fig. 1. Schematic of the major Fasciola -omics advances detailed over time. The 672 principal references are denoted by numbers as follows: 1) Dalton et al., 1985; 2)

673 Tkalcevic et al., 1995; 3) Jefferies et al., 2000; 4) Le et al., 2001; 5)

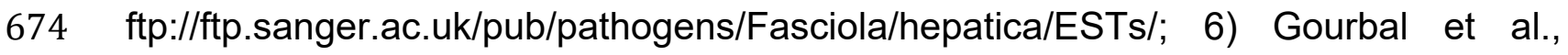

675 2008; 7) Robinson et al., 2009; 8) Young et al., 2010; 9) Cancela et al., 2010; 10)

676 Moxon et al., 2010; 11) Xu et al., 2012; 12) Marcilla et al., 2012; 13) Cwiklinski et al.,

677 2015a; 14) McNulty et al., 2017; 15) Garcia-Campos et al., 2016; 16) Ravida et al., 678 2016b; 17) Di Maggio et al., 2016.

679

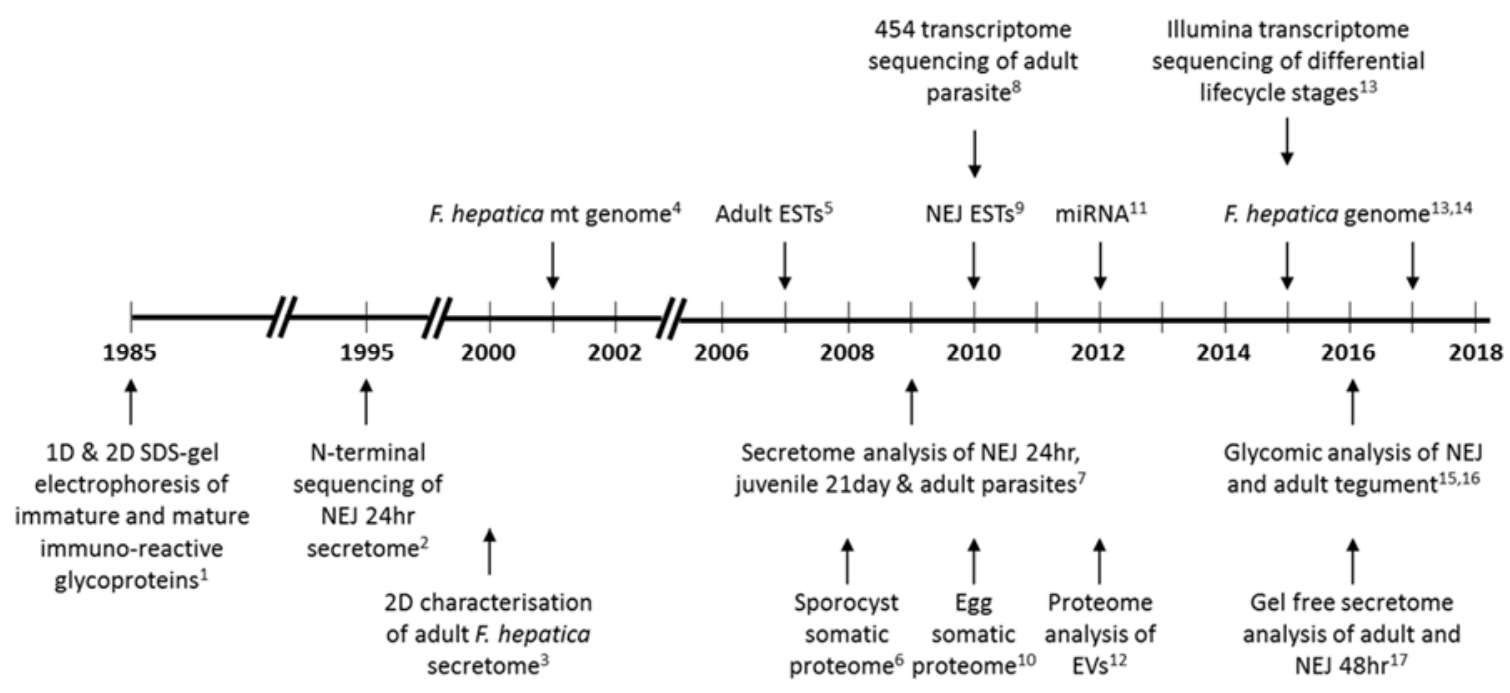


682 KC and JPD are funded by a European Research Council Advanced Grant 683 (HELIVAC, 322725) awarded to JPD and are members of the Horizon 2020-funded 684 Consortium PARAGONE.

685

686

\section{References}

Alvarez Rojas, C.A., Ansell, B.R., Hall, R.S., Gasser, R.B., Young, N.D., Jex, A.R., and Scheerlinck, J.P., 2015. Transcriptional analysis identifies key genes involved in metabolism, fibrosis/tissue repair and the immune response against Fasciola

690 hepatica in sheep liver. Parasit. Vectors 8, 124-015-0715-7.

Alvarez Rojas, C.A., Scheerlinck, J.P., Ansell, B.R., Hall, R.S., Gasser, R.B., and Jex, A.R., 2016. Time-course study of the transcriptome of peripheral blood mononuclear cells (PBMCs) from sheep infected with Fasciola hepatica. PLoS One $69411, \mathrm{e} 0159194$.

Andrews, S., 1999. The life cycle of Fasciola hepatica. In: Dalton, J.P. (Ed.), Fasciolosis. CABI Publishing, pp. 1-29.

697 Ardia, D.R., Parmentier, H.K., and Vogel, L.A., 2011. The role of constraints and 698 limitation in driving individual variation in immune response. Funct. Ecol. 25, 61-73.

699 Banford, S., Drysdale, O., Hoey, E.M., Trudgett, A., and Timson, D.J., 2013.

700 FhCaBP3: A Fasciola hepatica calcium binding protein with EF-hand and dynein light 701 chain domains. Biochimie 95, 751-758.

702 Bargues, M.D., Gayo, V., Sanchis, J., Artigas, P., Khoubbane, M., Birriel, S., and 703 Mas-Coma, S., 2017. DNA multigene characterization of Fasciola hepatica and 704 Lymnaea neotropica and its fascioliasis transmission capacity in Uruguay, with 705 historical correlation, human report review and infection risk analysis. PLoS Negl 706 Trop. Dis. 11, e0005352.

707 Beesley, N.J., Williams, D.J., Paterson, S., and Hodgkinson, J., 2017. Fasciola 708 hepatica demonstrates high levels of genetic diversity, a lack of population structure 709 and high gene flow: Possible implications for drug resistance. Int. J. Parasitol. 47, 710 11-20.

711 Bennett, H.M., Mok, H.P., Gkrania-Klotsas, E., Tsai, I.J., Stanley, E.J., Antoun, N.M., 712 Coghlan, A., Harsha, B., Traini, A., Ribeiro, D.M., Steinbiss, S., Lucas, S.B., Allinson, 713 K.S., Price, S.J., Santarius, T.S., Carmichael, A.J., Chiodini, P.L., Holroyd, N., Dean, 714 A.F., and Berriman, M., 2014. The genome of the sparganosis tapeworm Spirometra 715 erinaceieuropaei isolated from the biopsy of a migrating brain lesion. Genome Biol. $15,510$. 
Brewis, I.A., and Brennan, P., 2010. Proteomics technologies for the global identification and quantification of proteins. Adv. Protein Chem. Struct. Biol. 80, 1-44.

720 Cameron, T.C., Cooke, I., Faou, P., Toet, H., Piedrafita, D., Young, N., Rathinasamy,

721 V., Beddoe, R., Anderson, G., Dempster, R., and Spithill, T.W., 2017. A novel ex vivo immunoproteomic approach characterising Fasciola hepatica tegumental antigens identified using immune antibody from resistant sheep. Int. J. Parasitol. 47, 555-567.

Cancela, M., Ruetalo, N., Dell'Oca, N., da Silva, E., Smircich, P., Rinaldi, G., Roche, L., Carmona, C., Alvarez-Valin, F., Zaha, A., and Tort, J.F., 2010. Survey of transcripts expressed by the invasive juvenile stage of the liver fluke Fasciola hepatica. BMC Genomics 11, 227-2164-11-227.

728 Cancela, M., Santos, G.B., Carmona, C., Ferreira, H.B., Tort, J.F., and Zaha, A., 729 2015. Fasciola hepatica mucin-encoding gene: Expression, variability and its 730 potential relevance in host-parasite relationship. Parasitology 142, 1673-1681.

731 Cantacessi, C., Hofmann, A., Young, N.D., Broder, U., Hall, R.S., Loukas, A., and 732 Gasser, R.B., 2012. Insights into SCP/TAPS proteins of liver flukes based on largescale bioinformatic analyses of sequence datasets. PLoS One 7, e31164.

Chemale, G., Morphew, R., Moxon, J.V., Morassuti, A.L., Lacourse, E.J., Barrett, J., Johnston, D.A., and Brophy, P.M., 2006. Proteomic analysis of glutathione transferases from the liver fluke parasite, Fasciola hepatica. Proteomics 6, 62636273.

738 Chemale, G., Perally, S., LaCourse, E.J., Prescott, M.C., Jones, L.M., Ward, D., 739 Meaney, M., Hoey, E., Brennan, G.P., Fairweather, I., Trudgett, A., and Brophy, 740 P.M., 2010. Comparative proteomic analysis of triclabendazole response in the liver 741 fluke Fasciola hepatica. J. Proteome Res. 9, 4940-4951.

742 Coakley, G., Maizels, R.M., and Buck, A.H., 2015. Exosomes and other extracellular vesicles: The new communicators in parasite infections. Trends Parasitol. 31, 477489.

745 Correia, L., Podevin, P., Borderie, D., Verthier, N., Montet, J.C., Feldmann, G., 746 Poupon, R., Weill, B., and Calmus, Y., 2001. Effects of bile acids on the humoral 747 immune response: A mechanistic approach. Life Sci. 69, 2337-2348.

748 Cwiklinski, K., Dalton, J.P., Dufresne, P.J., La Course, J., Williams, D.J., 749 Hodgkinson, J., and Paterson, S., 2015a. The Fasciola hepatica genome: Gene 750 duplication and polymorphism reveals adaptation to the host environment and the 751 capacity for rapid evolution. Genome Biol. 16, 71-015-0632-2.

752 Cwiklinski, K., de la Torre-Escudero, E., Trelis, M., Bernal, D., Dufresne, P.J., 753 Brennan, G.P., O'Neill, S., Tort, J., Paterson, S., Marcilla, A., Dalton, J.P., and 754 Robinson, M.W., 2015b. The extracellular vesicles of the helminth pathogen, 
755 Fasciola hepatica: Biogenesis pathways and cargo molecules involved in parasite 756 pathogenesis. Mol. Cell. Proteomics 14, 3258-3273.

757 Dalton, J.P., Tom, T.D., and Strand, M., 1985. Fasciola hepatica: comparison of

758 immature and mature immunoreactive glycoproteins. Parasite Immunol. 7, 643-57.

759

760

761

762

763

764

765

766

767

768

769

770

771

772

773

774

775

776

777

778

779

780

781

782

783

784

785

786

787

788

789

790

791

de la Torre-Escudero, E., Bennett, A.P., Clarke, A., Brennan, G.P., and Robinson, M.W., 2016. Extracellular vesicle biogenesis in helminths: More than one route to the surface? Trends Parasitol. 32, 921-929.

Debey-Pascher, S., Hofmann, A., Kreusch, F., Schuler, G., Schuler-Thurner, B., Schultze, J.L., and Staratschek-Jox, A., 2011. RNA-stabilized whole blood samples but not peripheral blood mononuclear cells can be stored for prolonged time periods prior to transcriptome analysis. J. Mol. Diagn. 13, 452-460.

Di Maggio, L.S., Tirloni, L., Pinto, A.F., Diedrich, J.K., Yates lii, J.R., Benavides, U., Carmona, C., da Silva Vaz, I.,Jr, and Berasain, P., 2016. Across intra-mammalian stages of the liver fluke Fasciola hepatica: A proteomic study. Sci. Rep. 6, 32796.

Egger, G., Liang, G., Aparicio, A., and Jones, P.A., 2004. Epigenetics in human disease and prospects for epigenetic therapy. Nature 429, 457-463.

Eikmans, M., Rekers, N.V., Anholts, J.D., Heidt, S., and Claas, F.H., 2013. Blood cell mRNAs and microRNAs: Optimized protocols for extraction and preservation. Blood 121, e81-9.

El Andaloussi, S., Mager, I., Breakefield, X.O., and Wood, M.J., 2013. Extracellular vesicles: Biology and emerging therapeutic opportunities. Nat. Rev. Drug Discov. 12, 347-357.

ENCODE Project Consortium, 2012. An integrated encyclopedia of DNA elements in the human genome. Nature 489, 57-74.

Farina, A., Dumonceau, J.M., and Lescuyer, P., 2009. Proteomic analysis of human bile and potential applications for cancer diagnosis. Expert Rev. Proteomics 6, 285301.

Fontenla, S., Dell'Oca, N., Smircich, P., Tort, J.F., and Siles-Lucas, M., 2015. The miRnome of Fasciola hepatica juveniles endorses the existence of a reduced set of highly divergent microRNAs in parasitic flatworms. Int. J. Parasitol. 45, 901-913.

Fromm, B., Ovchinnikov, V., Hoye, E., Bernal, D., Hackenberg, M., and Marcilla, A., 2017. On the presence and immunoregulatory functions of extracellular microRNAs in the trematode Fasciola hepatica. Parasite Immunol. 39, 10.1111/pim.12399.

Fromm, B., Trelis, M., Hackenberg, M., Cantalapiedra, F., Bernal, D., and Marcilla, A., 2015. The revised microRNA complement of Fasciola hepatica reveals a plethora of overlooked microRNAs and evidence for enrichment of immuno-regulatory microRNAs in extracellular vesicles. Int. J. Parasitol. 45, 697-702. 
793 Mulcahy, G., 2016. Transcriptomic study on ovine immune responses to Fasciola

794 hepatica infection. PLoS Negl Trop. Dis. 10, e0005015.

795 Garcia-Campos, A., Baird, A.W., and Mulcahy, G., 2017. Migration of Fasciola 796 hepatica newly excysted juveniles is inhibited by high-mannose and oligomannose797 type N-glycan-binding lectins. Parasitology 144, 1708-1717.

798 Garcia-Campos, A., Ravida, A., Nguyen, D.L., Cwiklinski, K., Dalton, J.P., Hokke, 799 C.H., O'Neill, S., and Mulcahy, G., 2016. Tegument glycoproteins and cathepsins of 800 newly excysted juvenile Fasciola hepatica carry mannosidic and paucimannosidic N801 glycans. PLoS Negl. Trop. Dis. 10, e0004688.

802 Geyer, K.K., Chalmers, I.W., Mackintosh, N., Hirst, J.E., Geoghegan, R., Badets, M., 803 Brophy, P.M., Brehm, K., and Hoffmann, K.F., 2013. Cytosine methylation is a 804 conserved epigenetic feature found throughout the phylum Platyhelminthes. BMC 805 Genomics 14, 462-2164-14-462.

806 Gourbal, B.E., Guillou, F., Mitta, G., Sibille, P., Theron, A., Pointier, J.P., and 807 Coustau, C., 2008. Excretory-secretory products of larval Fasciola hepatica 808 investigated using a two-dimensional proteomic approach. Mol. Biochem. Parasitol. 809 161, 63-66.

810 Hacariz, O., Akgun, M., Kavak, P., Yuksel, B., and Sagiroglu, M.S., 2015.

811 Comparative transcriptome profiling approach to glean virulence and immunomodulation-related genes of Fasciola hepatica. BMC Genomics 16, 366-015813 1539-8.

814 Hacariz, O., Baykal, A.T., Akgun, M., Kavak, P., Sagiroglu, M.S., and Sayers, G.P., 815 2014. Generating a detailed protein profile of Fasciola hepatica during the chronic 816 stage of infection in cattle. Proteomics 14, 1519-1530.

817 Hacariz, O., Sayers, G., and Baykal, A.T., 2012. A proteomic approach to investigate 818 the distribution and abundance of surface and internal Fasciola hepatica proteins 819 during the chronic stage of natural liver fluke infection in cattle. J. Proteome Res. 11, 820 3592-3604.

821 Hernandez-Gonzalez, A., Valero, M.L., del Pino, M.S., Oleaga, A., and Siles-Lucas, 822 M., 2010. Proteomic analysis of in vitro newly excysted juveniles from Fasciola 823 hepatica. Mol. Biochem. Parasitol. 172, 121-128.

824 Hodgkinson, J., Cwiklinski, K., Beesley, N.J., Paterson, S., Williams, D.J., 2013. 825 Identification of putative markers of triclabendazole resistance by a genome-wide 826 analysis of genetically recombinant Fasciola hepatica. Parasitol. 140, 1523-1533

827 Howe, K.L., Bolt, B.J., Shafie, M., Kersey, P., and Berriman, M., 2017. WormBase 828 ParaSite - a comprehensive resource for helminth genomics. Mol. Biochem.

829 Parasitol. 215, 2-10. 
Huang-Doran, I., Zhang, C.Y., and Vidal-Puig, A., 2017. Extracellular vesicles: Novel mediators of cell communication in metabolic disease. Trends Endocrinol. Metab. 28, 3-18.

833 Ichikawa-Seki, M., Peng, M., Hayashi, K., Shoriki, T., Mohanta, U.K., Shibahara, T., and Itagaki, T., 2017. Nuclear and mitochondrial DNA analysis reveals that hybridization between Fasciola hepatica and Fasciola gigantica occurred in China. Parasitology 144, 206-213.

837 Irving D. O., and Howell, M.J., 1982. Characterization of excretory-secretory antigens of Fasciola hepatica. Parasitology 85, 179-188.

Itagaki, T., Ichinomiya, M., Fukuda, K., Fusyuku, S., and Carmona, C., 2011.

840 Hybridization experiments indicate incomplete reproductive isolating mechanism between Fasciola hepatica and Fasciola gigantica. Parasitology 138, 1278-1284.

842 Jarvis, E.D., 2016. Perspectives from the avian phylogenomics project: Questions that can be answered with sequencing all genomes of a vertebrate class. Annu. Rev. Anim. Biosci. 4, 45-59.

Jefferies, J.R., Brophy, P.M., and Barrett, J., 2000. Investigation of Fasciola hepatica sample preparation for two-dimensional electrophoresis. Electrophoresis 21, 3724-

8473729.

848 Jefferies, J.R., Campbell, A.M., van Rossum, A.J., Barrett, J., and Brophy, P.M., 849 2001. Proteomic analysis of Fasciola hepatica excretory-secretory products. 850 Proteomics 1, 1128-1132.

851 Knox, D.P., and Skuce, P.J., 2005. SAGE and the quantitative analysis of gene 852 expression in parasites. Trends Parasitol. 21, 322-326.

853

854

855

856

857

858

859

860

861

862

863

864

865

866

867

868

869

870
Koepfli, K.P., Paten, B., Genome 10K Community of Scientists, and O'Brien, S.J., 2015. The genome 10K project: A way forward. Annu. Rev. Anim. Biosci. 3, 57-111.

Lander, E.S., Linton, L.M., Birren, B., Nusbaum, C., Zody, M.C., Baldwin, J., Devon, K., Dewar, K., Doyle, M., FitzHugh, W., Funke, R., Gage, D., Harris, K., Heaford, A., Howland, J., Kann, L., Lehoczky, J., LeVine, R., McEwan, P., McKernan, K., Meldrim, J., Mesirov, J.P., Miranda, C., Morris, W., Naylor, J., Raymond, C., Rosetti, M., Santos, R., Sheridan, A., Sougnez, C., Stange-Thomann, Y., Stojanovic, N., Subramanian, A., Wyman, D., Rogers, J., Sulston, J., Ainscough, R., Beck, S., Bentley, D., Burton, J., Clee, C., Carter, N., Coulson, A., Deadman, R., Deloukas, P., Dunham, A., Dunham, I., Durbin, R., French, L., Grafham, D., Gregory, S., Hubbard, T., Humphray, S., Hunt, A., Jones, M., Lloyd, C., McMurray, A., Matthews, L., Mercer, S., Milne, S., Mullikin, J.C., Mungall, A., Plumb, R., Ross, M., Shownkeen, R., Sims, S., Waterston, R.H., Wilson, R.K., Hillier, L.W., McPherson, J.D., Marra, M.A., Mardis, E.R., Fulton, L.A., Chinwalla, A.T., Pepin, K.H., Gish, W.R., Chissoe, S.L., Wendl, M.C., Delehaunty, K.D., Miner, T.L., Delehaunty, A., Kramer, J.B., Cook, L.L., Fulton, R.S., Johnson, D.L., Minx, P.J., Clifton, S.W., Hawkins, T., Branscomb, E., Predki, P., Richardson, P., Wenning, S., Slezak, T., Doggett, N., Cheng, J.F., Olsen, A., Lucas, S., Elkin, C., Uberbacher, E., Frazier, M., Gibbs, R.A., 

Weinstock, G.M., Sakaki, Y., Fujiyama, A., Hattori, M., Yada, T., Toyoda, A., Itoh, T., Kawagoe, C., Watanabe, H., Totoki, Y., Taylor, T., Weissenbach, J., Heilig, R., Saurin, W., Artiguenave, F., Brottier, P., Bruls, T., Pelletier, E., Robert, C., Wincker, P., Smith, D.R., Doucette-Stamm, L., Rubenfield, M., Weinstock, K., Lee, H.M., Dubois, J., Rosenthal, A., Platzer, M., Nyakatura, G., Taudien, S., Rump, A., Yang, H., Yu, J., Wang, J., Huang, G., Gu, J., Hood, L., Rowen, L., Madan, A., Qin, S., Davis, R.W., Federspiel, N.A., Abola, A.P., Proctor, M.J., Myers, R.M., Schmutz, J., Dickson, M., Grimwood, J., Cox, D.R., Olson, M.V., Kaul, R., Raymond, C., Shimizu, N., Kawasaki, K., Minoshima, S., Evans, G.A., Athanasiou, M., Schultz, R., Roe, B.A., Chen, F., Pan, H., Ramser, J., Lehrach, H., Reinhardt, R., McCombie, W.R., de la Bastide, M., Dedhia, N., Blocker, H., Hornischer, K., Nordsiek, G., Agarwala, R., Aravind, L., Bailey, J.A., Bateman, A., Batzoglou, S., Birney, E., Bork, P., Brown, D.G., Burge, C.B., Cerutti, L., Chen, H.C., Church, D., Clamp, M., Copley, R.R., Doerks, T., Eddy, S.R., Eichler, E.E., Furey, T.S., Galagan, J., Gilbert, J.G., Harmon, C., Hayashizaki, Y., Haussler, D., Hermjakob, H., Hokamp, K., Jang, W., Johnson, L.S., Jones, T.A., Kasif, S., Kaspryzk, A., Kennedy, S., Kent, W.J., Kitts, P., Koonin, E.V., Korf, I., Kulp, D., Lancet, D., Lowe, T.M., McLysaght, A., Mikkelsen, T., Moran, J.V., Mulder, N., Pollara, V.J., Ponting, C.P., Schuler, G., Schultz, J., Slater, G., Smit, A.F., Stupka, E., Szustakowki, J., Thierry-Mieg, D., Thierry-Mieg, J., Wagner, L., Wallis, J., Wheeler, R., Williams, A., Wolf, Y.I., Wolfe, K.H., Yang, S.P., Yeh, R.F., Collins, F., Guyer, M.S., Peterson, J., Felsenfeld, A., Wetterstrand, K.A., Patrinos, A., Morgan, M.J., de Jong, P., Catanese, J.J., Osoegawa, K., Shizuya, H., Choi, S., Chen, Y.J., Szustakowki, J., and International Human Genome Sequencing Consortium, 2001. Initial sequencing and analysis of the human genome. Nature 409, 860-921.

898 Le, T.H., Blair, D., and McManus, D.P., 2001. Complete DNA sequence and gene 899 organization of the mitochondrial genome of the liverfluke, Fasciola hepatica $\mathrm{L}$. 900 (Platyhelminthes; Trematoda). Parasitology 123, 609-621.

901

902

903

904

905

906

907

908

909

910

911
Le, T.H., De, N.V., Agatsuma, T., Thi Nguyen, T.G., Nguyen, Q.D., McManus, D.P., and Blair, D., 2008. Human fascioliasis and the presence of hybrid/introgressed forms of Fasciola hepatica and Fasciola gigantica in Vietnam. Int. J. Parasitol. 38, 725-730.

Lee, C.G., Zimmerman, G.L., and Bishop, J.K., 1992a. Host influence on the banding profiles of whole-body protein and excretory-secretory product of Fasciola hepatica (Trematoda) by isoelectric focusing. Vet. Parasitol. 41, 57-68.

Lee, C.G., Zimmerman, G.L., and Mulrooney, D.M., 1992b. Isoelectric focusing of soluble proteins from Fasciola hepatica L, 1758 and Fascioloides magna B, 1875. Am. J. Vet. Res. 53, 246-250.

Liu, G.H., Gasser, R.B., Young, N.D., Song, H.Q., Ai, L., and Zhu, X.Q., 2014. Complete mitochondrial genomes of the 'intermediate form' of Fasciola and Fasciola gigantica, and their comparison with F. hepatica. Parasit. Vectors 7, 150-3305-7-150. 
914 Malone, J.H., and Oliver, B., 2011. Microarrays, deep sequencing and the true

915 measure of the transcriptome. BMC Biol. 9, 34-7007-9-34.

916 Marcilla, A., De la Rubia, J.E., Sotillo, J., Bernal, D., Carmona, C., Villavicencio, Z., 917 Acosta, D., Tort, J., Bornay, F.J., Esteban, J.G., and Toledo, R., 2008. Leucine 918 aminopeptidase is an immunodominant antigen of Fasciola hepatica excretory and

920 Marcilla, A., Martin-Jaular, L., Trelis, M., de Menezes-Neto, A., Osuna, A., Bernal, 921 D., Fernandez-Becerra, C., Almeida, I.C., and Del Portillo, H.A., 2014. Extracellular 922 vesicles in parasitic diseases. J. Extracell. Vesicles 3, 25040.

Marcilla, A., Trelis, M., Cortes, A., Sotillo, J., Cantalapiedra, F., Minguez, M.T., Valero, M.L., Sanchez del Pino, M.M., Munoz-Antoli, C., Toledo, R., and Bernal, D., 2012. Extracellular vesicles from parasitic helminths contain specific excretory/secretory proteins and are internalized in intestinal host cells. PLoS One 7, e45974.

929

930

931

932

933

934

935

936

937

938

939

940

941

942

943

944

945

946

947

948

949

950

951

952

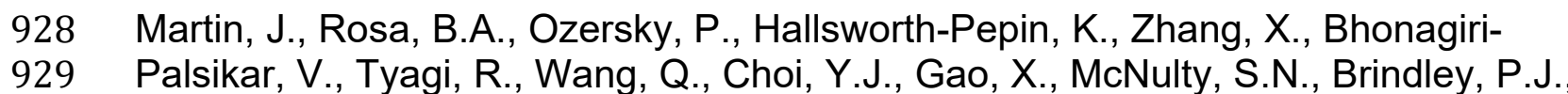
and Mitreva, M., 2015. Helminth.net: Expansions to nematode.net and an introduction to trematode.net. Nucleic Acids Res. 43, D698-706.

Martinez-Sernandez, V., Mezo, M., Gonzalez-Warleta, M., Perteguer, M.J., Muino, L., Guitian, E., Garate, T., and Ubeira, F.M., 2014. The MF6p/FhHDM-1 major antigen secreted by the trematode parasite Fasciola hepatica is a heme-binding protein. J. Biol. Chem. 289, 1441-1456.

Nature Method of the year 2012. 2013. Nat. Methods 10, 1.

McNulty, S.N., Tort, J.F., Rinaldi, G., Fischer, K., Rosa, B.A., Smircich, P., Fontenla, S., Choi, Y.J., Tyagi, R., Hallsworth-Pepin, K., Mann, V.H., Kammili, L., Latham, P.S., Dell'Oca, N., Dominguez, F., Carmona, C., Fischer, P.U., Brindley, P.J., and Mitreva, M., 2017. Genomes of Fasciola hepatica from the americas reveal colonization with neorickettsia endobacteria related to the agents of potomac horse and human sennetsu fevers. PLoS Genet. 13, e1006537.

Mi, H., Huang, X., Muruganujan, A., Tang, H., Mills, C., Kang, D., and Thomas, P.D., 2017. PANTHER version 11: expanded annotation data from Gene Ontology and Reactome pathways, and data analysis tool enhancements. Nucleic Acids Res. 45, D183-D189.

Morphew, R.M., Eccleston, N., Wilkinson, T.J., McGarry, J., Perally, S., Prescott, M., Ward, D., Williams, D., Paterson, S., Raman, M., Ravikumar, G., Khalid Saifullah, M., Abbas Abidi, S.M., McVeigh, P., Maule, A.G., Brophy, P.M., and LaCourse, E.J., 2012. Proteomics and in silico approaches to extend understanding of the glutathione transferase superfamily of the tropical liver fluke Fasciola gigantica. J. Proteome Res. 11, 5876-5889. 

Brophy, P.M., 2013. Identification of the major proteins of an immune modulating fraction from adult Fasciola hepatica released by nonidet P40. Vet. Parasitol. 191, 379-385.

957

958

959

960

961

962

963

964

965

966

967

968

969

970

971

972

973

974

975

976

977

978

979

980 981

982

983

984

985

986

987

988

989

990 Price, C.W., Leslie, D.C., and Landers, J.P., 2009. Nucleic acid extraction
991 techniques and application to the microchip. Lab. Chip 9, 2484-2494.

990 Price, C.W., Leslie, D.C., and Landers, J.P., 2009. Nucleic acid extractio
991 techniques and application to the microchip. Lab. Chip 9, 2484-2494.

Morphew, R.M., Wilkinson, T.J., Mackintosh, N., Jahndel, V., Paterson, S., McVeigh, P., Abbas Abidi, S.M., Saifullah, K., Raman, M., Ravikumar, G., LaCourse, J., Maule, A., and Brophy, P.M., 2016. Exploring and expanding the fatty-acid-binding protein superfamily in Fasciola species. J. Proteome Res. 15, 3308-3321.

Morphew, R.M., Wright, H.A., Lacourse, E.J., Porter, J., Barrett, J., Woods, D.J., and Brophy, P.M., 2011. Towards delineating functions within the Fasciola secreted cathepsin I protease family by integrating in vivo based sub-proteomics and phylogenetics. PLoS Negl. Trop. Dis. 5, e937.

Morphew, R.M., Wright, H.A., LaCourse, E.J., Woods, D.J., and Brophy, P.M., 2007. Comparative proteomics of excretory-secretory proteins released by the liver fluke Fasciola hepatica in sheep host bile and during in vitro culture ex host. Mol. Cell. Proteomics 6, 963-972.

Morphew, R.M., MacKintosh, N., Hart, E.H., Prescott, M., LaCourse, E.J., and Brophy, P.M., 2014. In vitro biomarker discovery in the parasitic flatworm Fasciola hepatica for monitoring chemotherapeutic treatment. EuPA Open Proteomics 3, 8599.

Moxon, J.V., LaCourse, E.J., Wright, H.A., Perally, S., Prescott, M.C., Gillard, J.L., Barrett, J., Hamilton, J.V., and Brophy, P.M., 2010. Proteomic analysis of embryonic Fasciola hepatica: Characterization and antigenic potential of a developmentally regulated heat shock protein. Vet. Parasitol. 169, 62-75.

Noel, E., Jarne, P., Glemin, S., MacKenzie, A., Segard, A., Sarda, V., and David, P., 2017. Experimental evidence for the negative effects of self-fertilization on the adaptive potential of populations. Curr. Biol. 27, 237-242.

Parkinson, J., and Blaxter, M., 2009. Expressed sequence tags: An overview. Methods Mol. Biol. 533, 1-12.

Peng, M., Ichinomiya, M., Ohtori, M., Ichikawa, M., Shibahara, T., and Itagaki, T., 2009. Molecular characterization of Fasciola hepatica, Fasciola gigantica, and aspermic Fasciola sp. in China based on nuclear and mitochondrial DNA. Parasitol. Res. 105, 809-815.

Poelchau, M., Childers, C., Moore, G., Tsavatapalli, V., Evans, J., Lee, C.Y., Lin, H., Lin, J.W., and Hackett, K., 2015. The i5k Workspace@NAL--enabling genomic data access, visualization and curation of arthropod genomes. Nucleic Acids Res. 43, D714-9. 
992 Ravida, A., Aldridge, A.M., Driessen, N.N., Heus, F.A., Hokke, C.H., and O'Neill,

993 S.M., 2016a. Fasciola hepatica surface coat glycoproteins contain mannosylated and 994 phosphorylated N-glycans and exhibit immune modulatory properties independent of 995 the mannose receptor. PLoS Negl. Trop. Dis. 10, e0004601.

996 Ravida, A., Cwiklinski, K., Aldridge, A.M., Clarke, P., Thompson, R., Gerlach, J.Q., 997 Kilcoyne, M., Hokke, C.H., Dalton, J.P., and O'Neill, S.M., 2016b. Fasciola hepatica 998 surface tegument: Glycoproteins at the interface of parasite and host. Mol. Cell. 999 Proteomics 15, 3139-3153.

1000 Record, M., Carayon, K., Poirot, M., and Silvente-Poirot, S., 2014. Exosomes as new 1001 vesicular lipid transporters involved in cell-cell communication and various pathophysiologies. Biochim. Biophys. Acta 1841, 108-120.

1003 Reuter, J.A., Spacek, D.V., and Snyder, M.P., 2015. High-throughput sequencing 1004 technologies. Mol. Cell 58, 586-597.

1005 Rioux, M.C., Carmona, C., Acosta, D., Ward, B., Ndao, M., Gibbs, B.F., Bennett, H.P., and Spithill, T.W., 2008. Discovery and validation of serum biomarkers expressed over the first twelve weeks of Fasciola hepatica infection in sheep. Int. J.

1008 Parasitol. 38, 123-136.

1009 Robinson, M.W., and Dalton, J.P., 2009. Zoonotic helminth infections with particular emphasis on fasciolosis and other trematodiases. Philos. Trans. R. Soc. Lond. B. Biol. Sci. 364, 2763-2776.

1012 Robinson, M.W., Donnelly, S., Hutchinson, A.T., To, J., Taylor, N.L., Norton, R.S., 1013 Perugini, M.A., and Dalton, J.P., 2011. A family of helminth molecules that modulate 1014 innate cell responses via molecular mimicry of host antimicrobial peptides. PLoS 1015 Pathog. 7, e1002042.

1016 Robinson, M.W., Menon, R., Donnelly, S.M., Dalton, J.P., and Ranganathan, S., 1017 2009. An integrated transcriptomics and proteomics analysis of the secretome of the 1018 helminth pathogen Fasciola hepatica: Proteins associated with invasion and infection 1019

1020 Robinson, M.W., Tort, J.F., Lowther, J., Donnelly, S.M., Wong, E., Xu, W., Stack, 1021 C.M., Padula, M., Herbert, B., and Dalton, J.P., 2008. Proteomics and phylogenetic analysis of the cathepsin $L$ protease family of the helminth pathogen Fasciola hepatica: Expansion of a repertoire of virulence-associated factors. Mol. Cell. Proteomics 7, 1111-1123.

1025 Rodriguez, E., Carasi, P., Frigerio, S., da Costa, V., van Vliet, S., Noya, V., 1026 Brossard, N., van Kooyk, Y., Garcia-Vallejo, J.J., and Freire, T., 2017. Fasciola 1027 hepatica immune regulates CD11c+ cells by interacting with the macrophage 1028 gal/GalNAc lectin. Front. Immunol. 8, 264.

1029 Rodriguez, E., Noya, V., Cervi, L., Chiribao, M.L., Brossard, N., Chiale, C., Carmona, 1030 C., Giacomini, C., and Freire, T., 2015. Glycans from Fasciola hepatica modulate the 
host immune response and TLR-induced maturation of dendritic cells. PLoS Negl Trop. Dis. 9, e0004234.

1033 Rojas-Caraballo, J., López-Abán, J., Fernández-Soto, P., Vicente, B., Collía, F., and 1034 Muro, A., 2015. Gene expression profile in the liver of BALB/c mice infected with 1035 Fasciola hepatica. PLoS One. 10, e0134910.

1036 Rojas-Caraballo, J., López-Abán, J., Moreno-Pérez, D.A., Vicente, B, FernándezSoto, P., Del Olmo, E., Patarroyo, M.A., and Muro, A., 2017. Transcriptome profiling of gene expression during immunisation trial against Fasciola hepatica: identification of genes and pathways involved in conferring immunoprotection in a murine model. BMC Infect. Dis. 17, 94.

1041 Roquis, D., Lepesant, J.M., Picard, M.A., Freitag, M., Parrinello, H., Groth, M., Emans, R., Cosseau, C., and Grunau, C., 2015. The epigenome of Schistosoma mansoni provides insight about how cercariae poise transcription until infection. PLoS Negl Trop. Dis. 9, e0003853.

1045 Ruiz-Campillo, M.T., Molina Hernandez, V., Escamilla, A., Stevenson, M., Perez, J., 1046 Martinez-Moreno, A., Donnelly, S., Dalton, J.P., and Cwiklinski, K., 2017. Immune 1047 signatures of pathogenesis in the peritoneal compartment during early infection of 1048 sheep with Fasciola hepatica. Sci. Rep. 7, 2782-017-03094-0.

1049 Sanabria, R., Ceballos, L., Moreno, L., Romero, J., Lanusse, C., and Alvarez, L., 2013. Identification of a field isolate of Fasciola hepatica resistant to albendazole and susceptible to triclabendazole. Vet. Parasitol. 193, 105-110.

Sanderson, A.R., 1953. Maturation and probable gynogenesis in the liver fluke, Science 270, 467-470. proteomic technologies. Methods Mol. Biol. 702, 163-190.

1059 Smith, D., Tikhonova, I.G., Jewhurst, H.L., Drysdale, O.C., Dvorak, J., Robinson, 1060 M.W., Cwiklinski, K., and Dalton, J.P., 2016. Unexpected activity of a novel kunitztype inhibitor: Inhibition of cysteine proteases but not serine proteases. J. Biol. Chem. 291, 19220-19234. more sensitive than EST for detecting low-abundance transcripts. BMC Genomics 5, 1.

1066 Szklarczyk, D., Franceschini, A., Wyder, S., Forslund, K., Heller, D., Huerta-Cepas, 1067 J., Simonovic, M., Roth, A., Santos, A., Tsafou, K.P., Kuhn, M., Bork, P., Jensen, 1068 L.J., and von Mering, C., 2015. STRING v10: protein-protein interaction networks, integrated over the tree of life. Nucleic Acids Res 43, D447-52. 
1070

1071

1072

1073

1074

1075

1076

1077

1078

1079

1080

1081

1082

1083

1084

1085

1086

1087

1088

1089

1090

1091

1092

1093

1094

1095

1096

1097

1098

1099

1100

1101

1102

1103

1104

1105

1106

1107

1108

1109

1110

1111

1112

1113

1114

1115
Taft, A.S., Vermeire, J.J., Bernier, J., Birkeland, S.R., Cipriano, M.J., Papa, A.R., McArthur, A.G., and Yoshino, T.P., 2009. Transcriptome analysis of Schistosoma mansoni larval development using serial analysis of gene expression (SAGE). Parasitology 136, 469-485.

Threadgold, L.T., 1976. Fasciola hepatica: Ultrastructure and histochemistry of the glycocalyx of the tegument. Exp. Parasitol. 39, 119-134.

Tkalcevic, J., Ashman, K., and Meeusen, E., 1995. Fasciola hepatica: Rapid identification of newly excysted juvenile proteins. Biochem. Biophys. Res. Commun. 213, 169-174.

van Die, I., and Cummings, R.D., 2010. Glycan gimmickry by parasitic helminths: A strategy for modulating the host immune response? Glycobiology 20, 2-12.

Venter, J.C., Adams, M.D., Myers, E.W., Li, P.W., Mural, R.J., Sutton, G.G., Smith, H.O., Yandell, M., Evans, C.A., Holt, R.A., Gocayne, J.D., Amanatides, P., Ballew, R.M., Huson, D.H., Wortman, J.R., Zhang, Q., Kodira, C.D., Zheng, X.H., Chen, L., Skupski, M., Subramanian, G., Thomas, P.D., Zhang, J., Gabor Miklos, G.L., Nelson, C., Broder, S., Clark, A.G., Nadeau, J., McKusick, V.A., Zinder, N., Levine, A.J., Roberts, R.J., Simon, M., Slayman, C., Hunkapiller, M., Bolanos, R., Delcher, A., Dew, I., Fasulo, D., Flanigan, M., Florea, L., Halpern, A., Hannenhalli, S., Kravitz, S., Levy, S., Mobarry, C., Reinert, K., Remington, K., Abu-Threideh, J., Beasley, E., Biddick, K., Bonazzi, V., Brandon, R., Cargill, M., Chandramouliswaran, I., Charlab, R., Chaturvedi, K., Deng, Z., Di Francesco, V., Dunn, P., Eilbeck, K., Evangelista, C., Gabrielian, A.E., Gan, W., Ge, W., Gong, F., Gu, Z., Guan, P., Heiman, T.J., Higgins, M.E., Ji, R.R., Ke, Z., Ketchum, K.A., Lai, Z., Lei, Y., Li, Z., Li, J., Liang, Y., Lin, X., Lu, F., Merkulov, G.V., Milshina, N., Moore, H.M., Naik, A.K., Narayan, V.A., Neelam, B., Nusskern, D., Rusch, D.B., Salzberg, S., Shao, W., Shue, B., Sun, J., Wang, Z., Wang, A., Wang, X., Wang, J., Wei, M., Wides, R., Xiao, C., Yan, C., Yao, A., Ye, J., Zhan, M., Zhang, W., Zhang, H., Zhao, Q., Zheng, L., Zhong, F., Zhong, W., Zhu, S., Zhao, S., Gilbert, D., Baumhueter, S., Spier, G., Carter, C., Cravchik, A., Woodage, T., Ali, F., An, H., Awe, A., Baldwin, D., Baden, H., Barnstead, M., Barrow, I., Beeson, K., Busam, D., Carver, A., Center, A., Cheng, M.L., Curry, L., Danaher, S., Davenport, L., Desilets, R., Dietz, S., Dodson, K., Doup, L., Ferriera, S., Garg, N., Gluecksmann, A., Hart, B., Haynes, J., Haynes, C., Heiner, C., Hladun, S., Hostin, D., Houck, J., Howland, T., Ibegwam, C., Johnson, J., Kalush, F., Kline, L., Koduru, S., Love, A., Mann, F., May, D., McCawley, S., Mclntosh, T., McMullen, I., Moy, M., Moy, L., Murphy, B., Nelson, K., Pfannkoch, C., Pratts, E., Puri, V., Qureshi, H., Reardon, M., Rodriguez, R., Rogers, Y.H., Romblad, D., Ruhfel, B., Scott, R., Sitter, C., Smallwood, M., Stewart, E., Strong, R., Suh, E., Thomas, R., Tint, N.N., Tse, S., Vech, C., Wang, G., Wetter, J., Williams, S., Williams, M., Windsor, S., Winn-Deen, E., Wolfe, K., Zaveri, J., Zaveri, K., Abril, J.F., Guigo, R., Campbell, M.J., Sjolander, K.V., Karlak, B., Kejariwal, A., Mi, H., Lazareva, B., Hatton, T., Narechania, A., Diemer, K., Muruganujan, A., Guo, N., Sato, S., Bafna, V., Istrail, S., Lippert, R., Schwartz, R., Walenz, B., Yooseph, S., Allen, D., Basu, A., Baxendale, J., Blick, L., Caminha, M., Carnes-Stine, J., Caulk, P., Chiang, Y.H., Coyne, M., Dahlke, C., Mays, A., Dombroski, M., Donnelly, M., Ely, D., Esparham, S., Fosler, C., Gire, H., Glanowski, S., Glasser, K., Glodek, A., Gorokhov, M., Graham, K., Gropman, B., Harris, M., Heil, J., Henderson, S., Hoover, J., Jennings, D., Jordan, C., Jordan, J., 
Kasha, J., Kagan, L., Kraft, C., Levitsky, A., Lewis, M., Liu, X., Lopez, J., Ma, D., Majoros, W., McDaniel, J., Murphy, S., Newman, M., Nguyen, T., Nguyen, N., Nodell, M., Pan, S., Peck, J., Peterson, M., Rowe, W., Sanders, R., Scott, J., Simpson, M., Smith, T., Sprague, A., Stockwell, T., Turner, R., Venter, E., Wang, M., Wen, M., Wu, D., Wu, M., Xia, A., Zandieh, A., and Zhu, X., 2001. The sequence of the human genome. Science 291, 1304-1351.

VerHague, M.A., Cheng, D., Weinberg, R.B., and Shelness, G.S., 2013. Apolipoprotein A-IV expression in mouse liver enhances triglyceride secretion and reduces hepatic lipid content by promoting very low density lipoprotein particle expansion. Arterioscler. Thromb. Vasc. Biol. 33, 2501-2508.

Walker, S.M., Johnston, C., Hoey, E.M., Fairweather, I., Borgsteede, F., Gaasenbeek, C., Prodohl, P.A., and Trudgett, A., 2011. Population dynamics of the liver fluke, Fasciola hepatica: The effect of time and spatial separation on the genetic diversity of fluke populations in the netherlands. Parasitology 138, 215-223.

Walker, S.M., Prodohl, P.A., Fletcher, H.L., Hanna, R.E., Kantzoura, V., Hoey, E.M., and Trudgett, A., 2007. Evidence for multiple mitochondrial lineages of Fasciola hepatica (liver fluke) within infrapopulations from cattle and sheep. Parasitol. Res. $101,117-125$.

Walker, S.M., Prodohl, P.A., Hoey, E.M., Fairweather, I., Hanna, R.E., Brennan, G., and Trudgett, A., 2012. Substantial genetic divergence between morphologically indistinguishable populations of Fasciola suggests the possibility of cryptic speciation. Int. J. Parasitol. 42, 1193-1199.

Wesołowska, A., Jaros, S., Norbury, L.J., Jaros, D., Zygner, W., and Wędrychowicz, $\mathrm{H}$., 2013. Microarray analysis of rat immune responses to liver fluke infection following vaccination with Fasciola hepatica phosphoglycerate kinase. Exp. Parasitol. 134, 33-8.

Williams, D.L., Sayed, A.A., Bernier, J., Birkeland, S.R., Cipriano, M.J., Papa, A.R., McArthur, A.G., Taft, A., Vermeire, J.J., and Yoshino, T.P., 2007. Profiling Schistosoma mansoni development using serial analysis of gene expression (SAGE). Exp. Parasitol. 117, 246-258.

Wilson, R.A., Wright, J.M., de Castro-Borges, W., Parker-Manuel, S.J., Dowle, A.A., Ashton, P.D., Young, N.D., Gasser, R.B., and Spithill, T.W., 2011. Exploring the Fasciola hepatica tegument proteome. Int. J. Parasitol. 41, 1347-1359.

Wuhrer, M., Berkefeld, C., Dennis, R.D., Idris, M.A., and Geyer, R., 2001. The liver flukes Fasicola gigantica and Fasciola hepatica express the leukocyte cluster of differentiation marker CD77 (globotriaosylceramide) in their tegument. Biol. Chem. 382, 195-207.

Wuhrer, M., Grimm, C., Zahringer U., Dennis, R.D., Berkefeld, C.M., Idris, M.A., and Geyer, R., 2003. A novel GlcNAcalpha1-HPO3-6Gal(1-1)ceramide antigen and alkylated inositol-phosphoglycerolipids expressed by the liver fluke Fasciola hepatica. Glycobiol. 13, 129-37. 
1157 Wuhrer, M., Grimm, C., Dennis, R.D., Idris, M.A., and Geyer, R., 2004. The parasitic 1158 trematode Fasciola hepatica exhibits mammalian-type glycolipids as well as 1159 Gal(beta1-6)Gal-terminating glycolipids that account for cestode serological cross1160 reactivity. Glycobiol. 14, 115-26.

1161 Xu, M.J., Ai, L., Fu, J.H., Nisbet, A.J., Liu, Q.Y., Chen, M.X., Zhou, D.H., and Zhu, 1162 X.Q., 2012. Comparative characterization of microRNAs from the liver flukes 1163 Fasciola gigantica and F. hepatica. PLoS One 7, e53387.

1164 Yarmush, M.L., and Jayaraman, A., 2002. Advances in proteomic technologies. 1165 Annu. Rev. Biomed. Eng. 4, 349-373.

1166 Young, N.D., Hall, R.S., Jex, A.R., Cantacessi, C., and Gasser, R.B., 2010.

1167 Elucidating the transcriptome of Fasciola hepatica - a key to fundamental and

1168 biotechnological discoveries for a neglected parasite. Biotechnol. Adv. 28, 222-231.

1169 Young, N.D., Jex, A.R., Cantacessi, C., Hall, R.S., Campbell, B.E., Spithill, T.W., 1170 Tangkawattana, S., Tangkawattana, P., Laha, T., and Gasser, R.B., 2011. A portrait 1171 of the transcriptome of the neglected trematode, Fasciola gigantica--biological and 1172 biotechnological implications. PLoS Negl Trop. Dis. 5, e1004. 